\title{
Different Doses of Palonosetron for the Prevention of Postoperative Nausea and Vomiting in Children Undergoing Strabismus Surgery
}

Cihangir Bicer, Recep Aksu, Ayse Ulgey, Halit Madenoglu, Hakki Dogan, Karamehmet Yildiz and Adem Boyaci

Anesthesiology and Reanimation Department, Erciyes University Medical Faculty, Kayseri, Turkey

Abstract
Background: Postoperative vomiting is a common complication after strabismus surgery in children. The serotonin $5-\mathrm{HT}_{3}$ receptor antagonists have proven to be a particularly valuable addition to the armamentarium against postoperative nausea and vomiting (PONV). Palonosetron is a secondgeneration $5-\mathrm{HT}_{3}$ receptor antagonist that has recently been approved for prophylaxis against PONV.

Objective: The aim of this study was to evaluate the efficacy of different doses of palonosetron for the prevention of PONV in children undergoing strabismus surgery.

Patients and Method: A total of 150 children who were classified with an American Society of Anesthesiologists physical status of I, were aged between 2 and 12 years, and were undergoing strabismus surgery under general anesthesia were enrolled in the study. A random numbers table was used to assign each child to receive palonosetron $0.5,1.0$, or $1.5 \mu \mathrm{g} / \mathrm{kg}(\mathrm{n}=50$ in each group). All episodes of PONV at the intervals of 0-2, 2-6, 6-24, and 24-48 hours were evaluated using a numeric scoring system for PONV. A p-value of $<0.05$ was considered statistically significant.

Results: The percentage of children with PONV during 0-48 hours after anesthesia was $24 \%$ with palonosetron 0.5 or $1.0 \mu \mathrm{g} / \mathrm{kg}$, and $20 \%$ with palonosetron $1.5 \mu \mathrm{g} / \mathrm{kg}$. There was no statistically significant difference between the study groups with respect to the number of children with PONV scores of 1,2 , or 3 during $0-48$ hours after anesthesia. There was no statistically significant difference between the study groups with respect to the number of children with postoperative vomiting during all time periods after anesthesia. The percentage of children aged $>6$ years with postoperative nausea during 0-48 hours after anesthesia was $8.6 \%, 18.2 \%$, and $15.4 \%$ with palonosetron $0.5,1.0$, or $1.5 \mu \mathrm{g} / \mathrm{kg}$, respectively, but there was no statistically significant difference between the study groups. 
Conclusion: Palonosetron doses of $0.5,1.0$, and $1.5 \mu \mathrm{g} / \mathrm{kg}$ are recommended for further evaluation, as they appear to be the effective doses for the prevention of PONV following strabismus surgery in children.

\section{Introduction}

Postoperative nausea and vomiting (PONV) is experienced by $41-88 \%$ of patients following strabismus surgery when antiemetic prophylactics are not administered. ${ }^{[1-3]}$ Since strabismus surgery is a notable independent risk factor for PONV in children, prophylactic administration of antiemetics is warranted. ${ }^{[4]}$ PONV after strabismus surgery has been studied with all classes of antiemetics, including butyrophenones, benzamides, histamine and muscarinic receptor antagonists, corticosteroids, and serotonin $5-\mathrm{HT}_{3}$ receptor antagonists. ${ }^{[5,6]}$ Persistent retching or vomiting can cause tension on suture lines, venous hypertension, increased bleeding, and can expose the subject to an increased risk of pulmonary aspiration of vomitus if airway reflexes are depressed from the residual effects of anesthetic and analgesic drugs. ${ }^{[7]}$ The area postrema of the brain stem, where the chemoreceptor trigger zone is located, is rich in dopamine, opioid, and 5- $\mathrm{HT}_{3}$ receptors. ${ }^{[8-10]}$ These receptors may play an important role in the transmission of impulses to the emetic center. ${ }^{[11]}$ The new generation of antiemetic agents, called $5-\mathrm{HT}_{3}$ receptor antagonists (e.g. ondansetron, granisetron, tropisetron, ramosetron, dolasetron), were superior to conventional antiemetics for the prevention and treatment of PONV in a review of clinical trials. ${ }^{[12]}$

Palonosetron, a second-generation $5-\mathrm{HT}_{3}$ receptor antagonist, has shown safe and effective therapeutic properties for the treatment of chemotherapy-induced nausea and vomiting (CINV) in children, and has a higher receptor affinity and a much longer half-life (approximately 40 hours) than other $5-\mathrm{HT}_{3}$ receptor antagonists. ${ }^{[13,14]} \mathrm{Pal}-$ onosetron has been used for the prevention of acute CINV in patients receiving either moderately or highly emetogenic chemotherapy, and for the prevention of delayed CINV in patients receiving moderately emetogenic chemotherapy. ${ }^{[15,16]}$
In a recent study, compared with the first-generation $5-\mathrm{HT}_{3}$ receptor antagonist granisetron, palonosetron in combination with dexamethasone demonstrated better control of delayed CINV in patients receiving highly emetogenic chemotherapy. ${ }^{[17]}$ Recent studies evaluated the efficacy and safety of palonosetron in preventing PONV.[18,19] However, to the best of our knowledge, palonosetron has never been used after strabismus surgery in children. This prospective, randomized, doubleblind, single-center study was designed to evaluate the efficacy of different doses of palonosetron for the prevention of PONV in children undergoing strabismus surgery.

\section{Materials and Methods}

After obtaining institutional review board approval and informed parental consent, a prospective, randomized, double-blind, single-center study was conducted. We enrolled 150 children from March 2009 to December 2009, who were classified with an American Society of Anesthesiologists physical status of I, were aged between 2 and 12 years, and were undergoing strabismus surgery under general anesthesia. Patients who had a history of motion sickness, prior severe PONV, known sensitivity to $5-\mathrm{HT}_{3}$ receptor antagonists, and who were using any other medication (especially those having an antiemetic effect, such as corticosteroids and phenothiazines, in the 24 hours before surgery) were not included in the study. Children did not consume milk or solid food for at least 6 hours before the operation; clear fluids were allowed until 3 hours before induction of anesthesia. No pre-anesthetic medications were administered.

For all patients, the age, sex, bodyweight, number of eyes and extraocular muscles operated on, the amount of fluid given intraoperatively, the agent used for the induction, duration of 
anesthesia, recovery time, number of vomiting episodes, and the number of patients receiving rescue antiemetic medication were recorded. Heart rhythm (assessed on ECG), non-invasive blood pressure, peripheral oxygen saturation, and endtidal $\mathrm{CO}_{2}$ were monitored and recorded before anesthesia induction (baseline), after induction, before study drug administration, 10 minutes after study drug administration, and 10 minutes after extubation.

Anesthesia induction was achieved with thiopental sodium $6 \mathrm{mg} / \mathrm{kg}$ or $8 \%$ sevoflurane in $50 \%$ $\mathrm{N}_{2} \mathrm{O}-\mathrm{O}_{2}$. Tracheal intubation was carried out after an injection of rocuronium bromide $0.6 \mathrm{mg} / \mathrm{kg}$. Nasogastric decompression was not performed in any patient. Anesthesia was maintained with $2 \%$ sevoflurane in $50 \% \mathrm{~N}_{2} \mathrm{O}-\mathrm{O}_{2}$, along with intravenous fentanyl $1.0 \mu \mathrm{g} / \mathrm{kg}$. A random numbers table was used to assign each child to receive palonosetron in a dose of $0.5,1.0$, or $1.5 \mu \mathrm{g} / \mathrm{kg}$ before induction of anesthesia. All study drugs were prepared in fixed volumes of $5 \mathrm{~mL}$ by an anesthetist who was not otherwise involved in patient care, in order to maintain the double-blind nature of the study.

Intraoperative intravenous fluid management consisted of administration of $5 \%$ dextrose with $0.3 \%$ saline sufficient to correct for half of the preoperative fluid deficit in the first hour, followed by maintenance fluids according to bodyweight.

At the end of surgery, residual neuromuscular blockade was antagonized with atropine $0.02 \mathrm{mg} / \mathrm{kg}$ and neostigmine $0.05 \mathrm{mg} / \mathrm{kg}$, and the trachea was extubated while the child was awake. The time for the patients to reach a score of 9 on Aldrete's postanesthetic recovery assessment ${ }^{[20]}$ after extubation was recorded as the recovery time. All episodes of PONV at the intervals of $0-2,2-6$, 6-24, and 24-48 hours were evaluated using a numeric scoring system for PONV $(0=$ no nausea or vomiting; 1 = nausea but no vomiting; $2=$ vomiting once in 30 minutes; $3=$ two or more episodes of vomiting in 30 minutes). Postoperatively, all episodes of retching and vomiting were recorded by nursing staff who did not know which treatment each patient had received. We did not assess nausea in very young children $(<6$ years). Any child having a score of 3 was considered to have severe vomiting and was treated with intravenous metoclopramide $150 \mu \mathrm{g} / \mathrm{kg}$ as a rescue antiemetic.

Postoperatively, analgesia was provided if older children reported pain or if younger children cried. Oral ibuprofen $10 \mathrm{mg} / \mathrm{kg}$ was given as the analgesic of first choice, and, for pain in children who had PONV in the immediate postoperative period in the postanesthesia care unit, meperidine $0.5 \mathrm{mg} / \mathrm{kg}$ was administered intravenously as the analgesic of second choice by the anesthesiologist who provided intraoperative care. Potential adverse events due to the study drug, such as headache and constipation, were also recorded after the operation by either questioning the children, interviewing the parents of the patients, or observation by the nurses.

The primary objective of the study was to determine the dose-response relationship of single intravenous doses of palonosetron $(0.5,1.0$, or $1.5 \mu \mathrm{g} / \mathrm{kg}$ ) for the prevention of PONV in children undergoing strabismus surgery. The primary outcome variable was the proportion of patients with PONV during the 48-hour period following surgery. Secondary measures were assessed for 48 hours after strabismus surgery and included the number of children with PONV scores of 1,2, and 3 , the number of children who needed rescue antiemetic, and assessment of potential adverse events.

\section{Statistical Analysis}

The primary efficacy hypotheses of the study were that (i) there is no difference in the proportion of patients with no nausea or emetic episodes between the groups receiving palonosetron $0.5,1.0$, or $1.5 \mu \mathrm{g} / \mathrm{kg}$; and (ii) each dose of palonosetron is able to induce a decrease of at least $50 \%$ in the incidence of PONV in the study population compared with the control population (i.e. patients receiving no antiemetic prophylaxis). Tosun et al. ${ }^{[21]}$ have previously reported the incidence of PONV in children undergoing strabismus surgery as $60 \%$ in our clinic. With respect to that study, using $\alpha=0.05$ and $\beta=0.2$ for each comparison, the sample size in the current study was estimated at 48 evaluable patients per group, 
rounded up to 50 patients per group (Sample-Size Software, NCSS-PASS, Kaysville, UT, USA). Statistical analyses were performed using SPSS (version 15.0, SPSS, Inc., Chicago, IL, USA) software. Whether the data had normal distribution or not was assessed by the Kolmogorov-Smirnov test. A one-way ANOVA test was used for the comparison of the parametric data with normal distribution between the groups. Statistical significance was determined by the Tukey Test, which is a post hoc multiple-comparison test. The repeated measures ANOVA test was performed for in-group comparisons. For the evaluation of parametric data without normal distribution, the Kruskal-Wallis test was used. PONV, induction agent, rescue antiemetic, operated eye and extraocular muscles, adverse effects, and sex were evaluated by the Chi-squared test. A p-value of $<0.05$ was accepted as statistically significant.

\section{Results}

The demographic data and clinical data, such as patient age, sex, bodyweight, intraoperative fluid requirement, duration of surgery, recovery time, and postoperative analgesic drug requirements were similar among all groups (table I). A total of 20,20, and 15 patients had an inhalation induction of anesthesia with $8 \%$ sevoflurane in $50 \% \mathrm{~N}_{2} \mathrm{O}-\mathrm{O}_{2}$, and 30,30 , and 35 patients had an intravenous induction of anesthesia with thiopental sodium $6 \mathrm{mg} / \mathrm{kg}$ in the palonosetron $0.5,1.0$, and $1.5 \mu \mathrm{g} / \mathrm{kg}$ groups, respectively.

The number of children who needed metoclopramide as a rescue antiemetic was five, two, and one in the palonosetron $0.5,1.0$, and $1.5 \mu \mathrm{g} / \mathrm{kg}$ groups, respectively, but the difference was not statistically significant (table I). None of the children in all three study groups had vomiting after the intravenous metoclopramide $150 \mu \mathrm{g} / \mathrm{kg}$ rescue injection.

The percentage of children with PONV during 0-48 hours after anesthesia was $24 \%$ with palonosetron $0.5 \mu \mathrm{g} / \mathrm{kg}$ (12 patients) and $1.0 \mu \mathrm{g} / \mathrm{kg}$ (12 patients), and $20 \%$ (10 patients) with palonosetron $1.5 \mu \mathrm{g} / \mathrm{kg}$.

There was no statistically significant difference between the study groups with respect to the number of children with PONV scores of 1,2, or 3 during 0-48 hours after anesthesia (table II).

During all time periods after anesthesia, there was no statistically significant difference between the study groups with respect to the number of children with vomiting (table II).

The percentage of children aged $>6$ years with nausea during 0-48 hours after anesthesia was $8.6 \%$ (three patients), $18.2 \%$ (six patients), and $15.4 \%$ (six patients) with palonosetron $0.5,1.0$, or $1.5 \mu \mathrm{g} / \mathrm{kg}$, respectively, but there was no statistically significant difference between the study groups (table II).

There was no statistically significant difference between the study groups with respect to the type

Table I. Demographic and clinical data

\begin{tabular}{|c|c|c|c|c|}
\hline \multirow[t]{2}{*}{ Characteristic } & \multicolumn{3}{|c|}{ Palonosetron dose } & \multirow[t]{2}{*}{$\overline{p-V a l u e}$} \\
\hline & $\begin{array}{l}0.5 \mu \mathrm{g} / \mathrm{kg} \\
(\mathrm{n}=50)\end{array}$ & $\begin{array}{l}1.0 \mu \mathrm{g} / \mathrm{kg} \\
(\mathrm{n}=50)\end{array}$ & $\begin{array}{l}1.5 \mu \mathrm{g} / \mathrm{kg} \\
(\mathrm{n}=50)\end{array}$ & \\
\hline$\overline{\text { Age }(y)[\text { mean } \pm S D]}$ & $7.94 \pm 3.1$ & $7.68 \pm 3.3$ & $8.36 \pm 3.0$ & 0.566 \\
\hline Bodyweight (kg) [mean \pm SD] & $28.7 \pm 11.2$ & $27.9 \pm 12.4$ & $29.3 \pm 11.8$ & 0.835 \\
\hline $\operatorname{Sex}(M / F)[n(\%)]$ & $24(48) / 26(52)$ & $25(50) / 25(50)$ & $28(56) / 22(44)$ & 0.707 \\
\hline Induction agent (sevoflurane/thiopental) [n (\%)] & $20(40) / 30(60)$ & $20(40) / 30(60)$ & $15(30) / 35(70)$ & 0.488 \\
\hline Intraoperative fluid (mL) [median (range)] & $200(100-500)$ & $200(50-500)$ & $200(70-600)$ & 0.888 \\
\hline Duration of surgery $(\mathrm{min})$ [mean $\pm \mathrm{SD}]$ & $47.7 \pm 16.4$ & $45.2 \pm 16.3$ & $47.9 \pm 16.8$ & 0.663 \\
\hline Recovery time (min) [mean \pm SD] & $8.9 \pm 4.1$ & $10.0 \pm 4.7$ & $9.7 \pm 4.7$ & 0.415 \\
\hline Rescue antiemetic in hospital [n (\%)] & $5(10)$ & $2(4)$ & $1(2)$ & 0.180 \\
\hline Postoperative requirements of IV meperidine [n (\%)] & $7(14)$ & $5(10)$ & $3(6)$ & 0.411 \\
\hline Postoperative requirements of oral ibuprofen [n (\%)] & $13(26)$ & $15(30)$ & $16(32)$ & 0.798 \\
\hline
\end{tabular}


Table II. Incidence and severity of postoperative nausea and vomiting $\left(\right.$ PONV) ${ }^{\mathrm{a}}$

\begin{tabular}{lcccc}
\hline Efficacy endpoint & \multicolumn{3}{l}{ Palonosetron dose } & p-Value \\
\cline { 2 - 3 } & $\begin{array}{l}0.5 \mu \mathrm{g} / \mathrm{kg} \\
(\mathrm{n}=50)\end{array}$ & $\begin{array}{l}1.0 \mu \mathrm{g} / \mathrm{kg} \\
(\mathrm{n}=50)\end{array}$ & $\begin{array}{l}1.5 \mu \mathrm{g} / \mathrm{kg} \\
(\mathrm{n}=50)\end{array}$ & \\
\hline PONV score & (0-48 $\mathrm{h})$ & & \\
0 & $38(76)$ & $38(76)$ & $40(80)$ & 0.859 \\
1 & $2(4)$ & $5(10)$ & $4(8)$ & 0.503 \\
2 & $5(10)$ & $5(10)$ & $5(10)$ & 1.000 \\
3 & $5(10)$ & $2(4)$ & $1(2)$ & 0.180 \\
Vomiting during postoperative time interval (h) & \\
$0-2$ & $10(20)$ & $7(14)$ & $7(14)$ & 0.640 \\
$2-6$ & $1(2)$ & $0(0)$ & $1(2)$ & 0.602 \\
$6-24$ & $0(0)$ & $0(0)$ & $0(0)$ & \\
$24-48$ & $0(0)$ & $0(0)$ & $0(0)$ & \\
$0-48$ & $11(22)$ & $7(14)$ & $8(16)$ & 0.272 \\
Nausea ${ }^{\mathrm{c}}$ during postoperative time interval (h) & \\
$0-2$ & $1(2.9)$ & $5(15.2)$ & $6(15.4)$ & 0.161 \\
$2-6$ & $2(5.7)$ & $1(3)$ & $0(0)$ & 0.330 \\
$6-24$ & $0(0)$ & $0(0)$ & $0(0)$ & \\
$24-48$ & $0(0)$ & $0(0)$ & $0(0)$ & \\
$0-48$ & $3(8.6)$ & $6(18.2)$ & $6(15.4)$ & 0.497 \\
\hline
\end{tabular}

a Values are expressed as $n(\%)$.

b $0=$ no nausea or vomiting; $1=$ nausea but no vomiting; $2=$ vomiting once in 30 minutes; $3=$ two or more episodes of vomiting in 30 minutes.

c Nausea was only assessed in patients aged $>6$ years: palonosetron $0.5 \mu \mathrm{g} / \mathrm{kg}(\mathrm{n}=35), 1.0 \mu \mathrm{g} / \mathrm{kg}(\mathrm{n}=33)$, and $1.5 \mu \mathrm{g} / \mathrm{kg}(\mathrm{n}=39)$.

of surgery conducted (e.g. recession, advancement [resection], myotomy, muscle resection or recession dosages $[\mathrm{mm}]$ ), or number of muscles repaired (table III).

In this study, all doses of palonosetron were well tolerated. Clinically serious adverse events (e.g. headache, constipation) caused by the study drug were not observed in any of the study groups. There was no statistically significant difference between study groups with respect to mean arterial blood pressures and heart rates recorded perioperatively.

\section{Discussion}

The reported incidence of PONV after pediatric strabismus surgery was $60 \%{ }^{[21]}$ and $85 \%{ }^{[22]}$ in previously published studies when no prophy- lactic antiemetic is given. The primary outcome of the current study was to determine the doseresponse relationship of single intravenous doses of palonosetron for the prevention of PONV in children undergoing strabismus surgery. The study demonstrated that $0.5 \mu \mathrm{g} / \mathrm{kg}$ of palonosetron was as effective as higher doses in reducing the incidence of PONV.

In the literature, there are only a few clinical studies for the use of palonosetron in the prevention of PONV in specific surgical situations. ${ }^{[18,23]}$ These specific situations were laparoscopic abdominal or gynecologic surgery, and major gynecologic surgery. White and Scuderi ${ }^{[23]}$ used palonosetron in a range of $0.1-30 \mu \mathrm{g} / \mathrm{kg}$ doses in abdominal or vaginal hysterectomy procedures and reported that intravenous palonosetron 1 and $30 \mu \mathrm{g} / \mathrm{kg}$ significantly reduced PONV compared with placebo treatment. In another study comparing the efficacy and safety of three different doses of palonosetron $(0.025,0.050$, and $0.075 \mathrm{mg}$ ) with placebo for the prevention of PONV for up to 72 hours in women undergoing general anesthesia for elective gynecologic or breast surgery, the authors reported that a single $0.075 \mathrm{mg}$ dose of intravenous palonosetron (i) significantly increased the rates of no emetic episodes and no rescue medication from 0 to 24 hours ( $p=0.004)$; (ii) decreased nausea severity $(\mathrm{p}=0.042)$; and (iii) significantly decreased interference in patient postoperative recovery due to PONV $(p=0.004) .{ }^{[18]}$ Sepúlveda-Vildósola et al. ${ }^{[14]}$ used palonosetron $3-19 \mu \mathrm{g} / \mathrm{kg}$ to prevent CINV in children, and concluded that palonosetron is a safe and effective antiemetic drug in this patient population. However, no studies have evaluated the dose-response and clinical usefulness of prophylactic palonosetron in children undergoing strabismus repair (a procedure that carries the high risk of PONV) alone.

In the present study, we compare three different doses of palonosetron $(0.5,1.0$, and $1.5 \mu \mathrm{g} / \mathrm{kg})$ to find the lowest dose of palonosetron that is effective in preventing PONV in children undergoing strabismus surgery. Dose selection was based on findings of an earlier study that evaluated intravenous doses of palonosetron ranging from 0.1 to $30 \mu \mathrm{g} / \mathrm{kg} .{ }^{[23]}$ Our study is the first to 
Table III. The number of operated eyes and extraocular muscles, and type of surgery

\begin{tabular}{|c|c|c|c|c|}
\hline \multirow[t]{2}{*}{ Efficacy endpoint } & \multicolumn{3}{|c|}{ Palonosetron dose } & \multirow[t]{2}{*}{$\mathrm{p}$-Value } \\
\hline & $\begin{array}{l}0.5 \mu \mathrm{g} / \mathrm{kg} \\
(\mathrm{n}=50)\end{array}$ & $\begin{array}{l}1.0 \mu \mathrm{g} / \mathrm{kg} \\
(\mathrm{n}=50)\end{array}$ & $\begin{array}{l}1.5 \mu \mathrm{g} / \mathrm{kg} \\
(\mathrm{n}=50)\end{array}$ & \\
\hline Surgery of one eye/both eyes (n) & $28 / 22$ & $26 / 24$ & $26 / 24$ & 0.898 \\
\hline \multicolumn{5}{|l|}{ Type of surgery } \\
\hline advancement [resection] (n) & 0 & 1 & 1 & 0.602 \\
\hline recession $(n)$ & 11 & 15 & 13 & 0.660 \\
\hline advancement and recession $(n)$ & 19 & 12 & 17 & 0.303 \\
\hline myotomy (n) & 20 & 22 & 19 & 0.824 \\
\hline \multicolumn{5}{|l|}{ Surgical dosages } \\
\hline resection $(\mathrm{mm})[$ mean $\pm \mathrm{SD}]$ & $6.7 \pm 0.8$ & $6.2 \pm 1.4$ & $6.5 \pm 1.6$ & 0.525 \\
\hline recession $(\mathrm{mm})[$ mean $\pm \mathrm{SD}]$ & $6.6 \pm 2.7$ & $6.2 \pm 1.3$ & $6.1 \pm 1.7$ & 0.709 \\
\hline \multicolumn{5}{|c|}{ Number of operated muscles (n/PONV) } \\
\hline 1 & $9 / 3$ & $15 / 4$ & $10 / 1$ & $>0.05$ \\
\hline 2 & $38 / 7$ & $31 / 6$ & $36 / 9$ & $>0.05$ \\
\hline 3 & $2 / 2$ & $1 / 1$ & $2 / 0$ & $>0.05$ \\
\hline 4 & $1 / 0$ & $3 / 1$ & $2 / 0$ & $>0.05$ \\
\hline
\end{tabular}

make a recommendation of palonosetron dose based on comparison among three different bodyweight-adjusted doses in children undergoing strabismus surgery. This is especially important in pediatric patients, because the use of predetermined doses irrespective of bodyweight may lead to administration of either an inadequate or an excessive dose of palonosetron resulting in lack of efficacy or occurrence of adverse effects, respectively.

The incidence of PONV in our palonosetron groups was similar to that reported in previous $5-\mathrm{HT}_{3}$ inhibitor studies. ${ }^{[21,24,25]}$ The elimination half-life of palonosetron (reported to be approximately 40 hours $^{[13]}$ ) is longer than that of other $5-\mathrm{HT}_{3}$ receptor antagonists (e.g. granisetron 5-8 hours, ondansetron 3-5 hours, ramosetron 4.3-9 hours, tropisetron 8 hours). This long halflife permits one dose of palonosetron to be enough for the prevention of PONV after strabismus surgery.

In this study, the groups were comparable with respect to patient characteristics, hemodynamic variables, surgical procedure (recession, resection, and myotomy), and anesthetics administered. Therefore, any difference in the incidence and severity of PONV among the groups in this study could be attributed to the three different doses of the study antiemetic that was administered.

Due to the increasing cost of care for PONV, cost effectiveness continues to be a major concern when choosing therapeutic agents. Proper dosage, the emetic potential of the surgical procedure and anesthetic agents, and patient history of response to $5-\mathrm{HT}_{3}$ receptor antagonists are important factors to consider when choosing agents within the class. However, there is a large cost difference between palonosetron and other $5-\mathrm{HT}_{3}$ receptor antagonists. With respect to palonosetron, it is difficult to decide how much added cost the added benefit is worth.

One possible limitation of this study was that we could not compare the effect of palonosetron with placebo. More than half of all patients undergoing pediatric strabismus surgery experience PONV and, therefore, it would be unethical to use a placebo group in this pediatric population. Another possible limitation of this study may be the short duration of the study period (48 hours). Due to both the long half-life and long-lasting functional effects of palonosetron compared with other $5-\mathrm{HT}_{3}$ receptor antagonists, PONV may be assessed for 72 hours; however, in our study, patients were discharged from the hospital after 
48 hours, and parents were not contacted the day after hospital discharge for further assessment of PONV and potential adverse effects.

The low population size for a dose-response trial is also a limitation of this study, with perhaps too few patients in each treatment group for a robust statistical evaluation of the treatment effect on all endpoints and at all time intervals to be conducted. An example of this limitation was the low rate of rescue medication use in the palonosetron $1.5 \mu \mathrm{g} / \mathrm{kg}$ (one patient) group compared with that observed in the $0.5 \mu \mathrm{g} / \mathrm{kg}$ (five patients) and $1.0 \mu \mathrm{g} / \mathrm{kg}$ (two patients) groups during the 0 - to 48 -hour interval after surgery. Although there was a reduction in the incidence of rescue medication use, it did not prove to be statistically significant $(p=0.180)$. Due to the overall low rate of rescue medication use, it is difficult to make conclusions about the efficacy of the drug in this respect.

Based on the results of this study, fixed palonosetron doses of $0.5,1.0$, and $1.5 \mu \mathrm{g} / \mathrm{kg}$ are recommended for further evaluation, as they appear to be the effective doses for the prevention of PONV following strabismus surgery in children.

\section{Acknowledgments}

No sources of funding were used to conduct this study or prepare this article. The authors have no conflicts of interest that are directly relevant to the content of this article.

\section{References}

1. Hardy JF, Charest J, Girouard G, et al. Nausea and vomiting after strabismus surgery in preschool children. Can Anaesth Soc J 1986; 33 (1): 57-62

2. Lin DM, Furst SR, Rodarte A. A double-blinded comparison of metoclopramide and droperidol for prevention of emesis following strabismus surgery. Anesthesiology 1992; 76 (3): 357-61

3. Kovac AL. Management of postoperative nausea and vomiting in children. Paediatr Drugs 2007; 9: 47-69

4. Van den Bosch JE, Moons KG, Bonsel GJ, et al. Does measurement of preoperative anxiety have added value for predicting postoperative nausea and vomiting? Anesth Analg 2005; 100: 1525-32

5. Habib AS, Gan TJ. Evidence-based management of postoperative nausea and vomiting: a review. Can J Anesth 2004; 51: 326-41
6. Madan R, Bhatia A, Chakithandy S, et al. Prophylactic dexamethasone for postoperative nausea and vomiting in pediatric strabismus surgery: a dose ranging and safety evaluation study. Anesth Analg 2005; 100: 1622-6

7. Vance JP, Neill RS, Norris W. The incidence and aetiology of post-operative nausea and vomiting in a plastic surgical unit. Br J Plast Surg 1973; 26 (4): 336-9

8. Stefanini E, Clement-Cormier Y. Detection of receptors in the area postrema. Eur J Pharmacol 1981; 74: 257-60

9. Atweh SF, Kuhar MJ. Autoradiographic localization of opiate receptors in rat brain. II: the brain stem. Brain Res 1977; 129: 1-12

10. Waeber C, Dixon K, Hoyer D, et al. Localisation by autoradiography of neuronal $5-\mathrm{HT}_{3}$ receptors in the mouse CNS. Eur J Pharmacol 1988; 151: 351-2

11. Watcha MF, White PF. Postoperative nausea and vomiting: its etiology, treatment, and prevention. Anesthesiology 1992; 77: 162-84

12. Loewen PS, Marra CA, Zed PJ. 5-HT 3 receptor antagonists vs traditional agents for the prophylaxis of postoperative nausea and vomiting. Can J Anaesth 2000; 47: 1008-18

13. Muchatuta NA, Paech MJ. Management of postoperative nausea and vomiting: focus on palonosetron. Ther Clin Risk Manag 2009; 5: 21-34

14. Sepúlveda-Vildósola AC, Betanzos-Cabrera Y, Lastiri GG, et al. Palonosetron hydrochloride is an effective and safe option to prevent chemotherapy-induced nausea and vomiting in children. Arch Med Res 2008; 39: 601-6

15. Eisenberg P, Figueroa-Vadillo J, Zamora R, et al. Improved prevention of moderately emetogenic chemotherapy-induced nausea and vomiting with palonosetron, a pharmacologically novel $5-\mathrm{HT}_{3}$ receptor antagonist: results of a phase III, single-dose trial versus dolasetron. Cancer 2003; 98: 2473-82

16. Gralla R, Lichinitser M, Van Der Vegt S, et al. Palonosetron improves prevention of chemotherapy-induced nausea and vomiting following moderately emetogenic chemotherapy: results of a double-blind randomized phase III trial comparing single doses of palonosetron with ondansetron. Ann Oncol 2003; 14: 1570-7

17. Saito M, Aogi K, Sekine I, et al. Palonosetron plus dexamethasone versus granisetron plus dexamethasone for prevention of nausea and vomiting during chemotherapy: a double-blind, double-dummy, randomised, comparative phase III trial. Lancet Oncol 2009; 10: 115-24

18. Candiotti KA, Kovac AL, Melson TI, et al. A randomized, double-blind study to evaluate the efficacy and safety of three different doses of palonosetron versus placebo for preventing postoperative nausea and vomiting. Anesth Analg 2008; 107: 445-51

19. Kovac AL, Eberhart L, Kotarski J, et al. A randomized, double-blind study to evaluate the efficacy and safety of three different doses of palonosetron versus placebo in preventing postoperative nausea and vomiting over a 72-hour period. Anesth Analg 2008; 107: 439-44

20. Aldrete JA, Kroulik D. A postanesthetic recovery score. Anesth Analg 1970; 49: 924-34

21. Tosun Z, Akin A, Dogan H, et al. A randomized, placebocontrolled trial of a single dose of tropisetron for the prevention of vomiting after strabismus surgery in children. Mt Sinai J Med 2006; 73: 1106-11 
22. Abramowitz MD, Oh TH, Epstein BS, et al. The antiemetic effect of droperidol following outpatient strabismus surgery in children. Anesthesiology 1983; 59: 579-83

23. White PF, Scuderi PE. Prevention of postoperative nausea and vomiting (PONV): a dose-ranging study involving palonosetron, a potent $5-\mathrm{HT}_{3}$ receptor antagonist [abstract]. Anesthesiology 2005; 103: A703

24. Sadhasivam S, Shende D, Madan R. Prophylactic ondansetron in prevention of postoperative nausea and vomiting following pediatric strabismus surgery: a dose-response study. Anesthesiology 2000; 92: 1035-42
25. Fujii Y, Tanaka H, Ito M. A randomized clinical trial of a single dose of ramosetron for the prevention of vomiting after strabismus surgery in children: a dose-ranging study. Arch Ophthalmol 2005; 123: 25-8

Correspondence: Assistant Associate Professor Dr Cihangir Bicer, Anesthesiology and Reanimation Department, Erciyes University Medical Faculty, Melikgazi, Kayseri, 38039, Turkey.

E-mail: cbicer33@yahoo.com.tr 